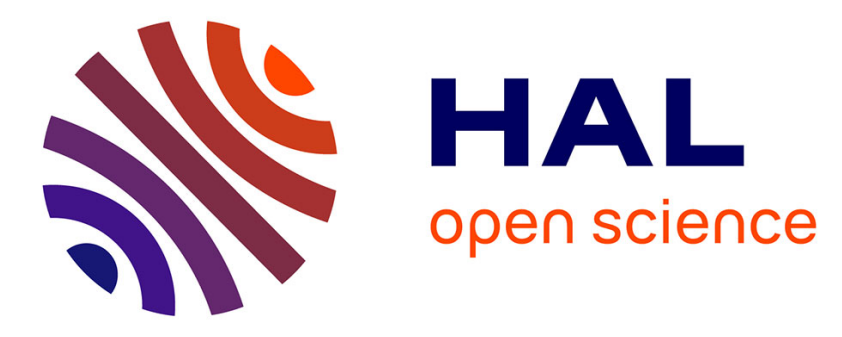

\title{
Water availability rather than temperature control soil fauna community structure and prey-predator interactions
}

\author{
Adriane Aupic-Samain, Virginie Baldy, Ninon Delcourt, Paul Henning Krogh, \\ Thierry Gauquelin, Catherine Fernandez, Mathieu Santonja
}

\section{To cite this version:}

Adriane Aupic-Samain, Virginie Baldy, Ninon Delcourt, Paul Henning Krogh, Thierry Gauquelin, et al.. Water availability rather than temperature control soil fauna community structure and preypredator interactions. Functional Ecology, 2021, 35 (7), pp.1550-1559. 10.1111/1365-2435.13745 . hal-03102477

\section{HAL Id: hal-03102477 \\ https://hal-amu.archives-ouvertes.fr/hal-03102477}

Submitted on 7 Jan 2021

HAL is a multi-disciplinary open access archive for the deposit and dissemination of scientific research documents, whether they are published or not. The documents may come from teaching and research institutions in France or abroad, or from public or private research centers.
L'archive ouverte pluridisciplinaire HAL, est destinée au dépôt et à la diffusion de documents scientifiques de niveau recherche, publiés ou non, émanant des établissements d'enseignement et de recherche français ou étrangers, des laboratoires publics ou privés. 


\section{Functional Ecology}

Title: Water availability rather than temperature control soil fauna community structure and preypredator interactions

Authors: Adriane Aupic-Samain ${ }^{1}$, Virginie Baldy ${ }^{1}$, Ninon Delcourt ${ }^{1}$, Paul Henning Krogh ${ }^{2}$, Thierry Gauquelin ${ }^{1}$, Catherine Fernandez ${ }^{1}$, Mathieu Santonja ${ }^{1}$

\section{Addresses}

1. Aix Marseille Univ, Avignon Université, CNRS, IRD, IMBE, Marseille, France.

2. Department of Bioscience, Aarhus University, Vejlsøvej 25, DK-8600 Silkeborg, Denmark.

\section{Email addresses}

Adriane Aupic-Samain (adriane.samain-aupic@imbe.fr)

Virginie Baldy (virginie.baldy@imbe.fr)

Ninon Delcourt (ninon.delcourt@imbe.fr)

Paul Henning Krogh (phk@bios.au.dk)

Thierry Gauquelin (thierry.gauquelin@imbe.fr)

Catherine Fernandez (catherine.fernandez@imbe.fr)

Mathieu Santonja (mathieu.santonja@imbe.fr)

\section{Corresponding author}

Adriane Aupic-Samain (adriane.samain-aupic@imbe.fr)

ORCID: https://orcid.org/0000-0002-6083-1709

\section{Acknowledgement}

We specially thank to Sylvie Dupouyet and Jean-Philippe Orts and Adoudé Adotevi for their technical assistance during the laboratory experiment. Funding was provided by AnaEE France for the $\mathrm{O}_{3} \mathrm{HP}$ facilities, the French Agence Nationale pour la Recherche (ANR) through the project SecPriMe2 (no. ANR-12-BSV7-0016-01), and the program BioDivMeX (BioDiversity of the Mediterranean eXperiment) of the meta-program MISTRALS (Mediterranean Integrated STudies at Regional And Local Scales). This research is also a contribution to the Labex OT-Med (no ANR-11-LABX-0061) funded by the "Investissements d'Avenir" program of the French

This article has been accepted for publication and undergone full peer review but has not been through the copyediting, typesetting, pagination and proofreading process, which may lead to differences between this version and the Version of Record. Please cite this article as doi: $\underline{10.1111 / 1365-2435.13745}$

This article is protected by copyright. All rights reserved 
National Research Agency through the A*MIDEX project (no ANR-11-IDEX-0001-02). Finally, the authors declare no conflict of interest.

\section{Author contributions}

MS and VB conceived the ideas and designed methodology. AAS, ND and MS collected the data. AAS and MS analysed the data and led the writing of the manuscript. All authors contributed critically to the drafts and gave final approval for publication.

\section{Data accessibility}

Th data supporting this article is available from the Dryad Digital Repository: https://doi.org/10.5061/dryad.brv15dv7t, (Aupic-Samain et al., 2020). 
MS ADRIANE AUPIC-SAMAIN (Orcid ID : 0000-0002-6083-1709)

DR PAUL HENNING KROGH (Orcid ID : 0000-0003-2033-553X)

DR MATHIEU SANTONJA (Orcid ID :0000-0002-6322-6352)

Article type : Research Article

Section: Other

Editor: Dr Maria Briones

\section{Abstract}

1. The ongoing climate change may strongly impact soil biodiversity with cascading effects on the processes they drive. Thus, it is of prime interest to improve our knowledge about responses by soil organisms such as collembolans to expected shifts in environmental conditions by considering communities comprising both detritivores and predators.

2. The aim of the present study was to evaluate how simulated climate change and predation under laboratory conditions alter a collembolan community.

3. To infer the impact of climate change, we applied a decreased level of soil moisture $(60 \%$ vs. $30 \%$ soil water holding capacity) and an increasing air temperature $\left(15^{\circ} \mathrm{C} v s .25^{\circ} \mathrm{C}\right)$ to a collembolan community constituted by four species (Folsomia candida, Protaphorura fimata, Proisotoma minuta and Mesaphorura macrochaeta) exhibiting distinct functional traits, e.g. body size and furca presence, in presence or absence of a predatory gamasid Acari (Stratiolaelaps scimitus) during two months in a microcosm experiment.

4. We observed that decreasing soil moisture altered the collembolan community with species-specific responses. Interaction between soil moisture, temperature and predation indicates that low soil moisture reduced total collembolan abundance especially i) by suppressing the positive effect of increasing temperature and ii) by increasing the predatory control on collembolan abundance.

This article is protected by copyright. All rights reserved 
5. These results highlight that soil moisture is the major driver of Collembola community and by consequence, a shift in climatic parameters with the ongoing climate change should strongly modify the Collembola community structure and the predator-prey interaction. Our findings are highly important since a strengthening of predation impact on Collembola prey could have major consequences on the whole soil food web being able to lead to a slowdown of key ecosystem processes they drive (e.g., litter decomposition and nutrient recycling). Finally, our study promotes the need to study more complex systems considering distinct soil-dwelling species, their functional traits and their trophic interactions to better predict the ecosystem responses to the ongoing climate change.

Keywords: Climate change; Collembola; functional trait; mite; soil moisture; springtail; topdown control; trophic interaction.

\section{Introduction}

In terrestrial ecosystems, soil biodiversity drives biogeochemical cycles (Bardgett, 2005; Berg \& Laskowski, 2005; Hättenschwiler, Tiunov, \& Scheu, 2005) supporting soil fertility (Scheu, Ruess \& Bonkowski 2005; Gobat, Aragno \& Matthey, 2013), plant growth (Van der Putten, Vet, Harvey \& Wäckers, 2001) and overall ecosystem functioning (Wardle, Bonner \& Barker, 2002; Gobat et al., 2013). Among soil organisms, Collembola is a widespread group of microbi-detritivore organisms (Hopkin, 1997). They play a crucial role in nutrient cycling by regulating soil microbial communities (Hättenschwiler et al., 2005; Chahartaghi, Langel, Scheu \& Ruess, 2005) and by micro-fragmenting litter (Gobat et al, 2013). Collembola also play a key role in structuring the soil food web, being both microbial consumer and prey of several predators including spiders (Lawrence \& Wise, 2000; VucicPestic, Birkhofer, Rall, Scheu \& Brose, 2010), centipedes (Günther, Rall, Ferlian, Scheu \& Eitzinger 2014; Kalinkat, Brose \& Rall, 2013) and predatory Acari (Koehler, 1999; Schneider \& Maraun, 2009; Thakur \& Eisenhauer, 2015; Aupic-Samain, Baldy, Lecareux, Fernandez \& Santonja, 2019). However, Collembola are strongly sensitive to environmental parameters such as soil humidity and air temperature (Harte, Rawa \& Price 1996; Hopkin, 1997; Lindberg \& Bengtsson, 2005; Santonja, Aupic-Samain, Forey \& Chauvat, 2018). Thereby, the ongoing climate change, such as reduced precipitation and increasing temperature predicted in the temperate and Mediterranean regions (IPCC, 2014; Dubrovský et al., 2014), may strongly impact Collembola communities by altering species demographic parameters (e.g. reproduction, growth rate and survival, Blankinship, Niklaus, \& Hungate, 2011; 
Santonja et al., 2017) and trophic interactions within the soil food web (Tylianakis, Didham, Bascompte, \& Wardle, 2008; Van der Putten, Macel \& Visser, 2010) with cascading effects on overall ecosystem functioning (Thakur et al., 2015; Santonja et al., 2017).

Despite a growing interest to predict the responses of organisms and the processes they drive to future climatic conditions, only few studies focus on soil organisms. Under elevated temperature, ectothermic organisms such as Collembola and their predators generally increase their activities (e.g., reproduction, growth rate, mobility, nutrition) within their thermal limits due to a higher metabolic demand (Gillooly, Brown, West, Savage \& Charnov, 2001; Vucic-Pestic et al., 2010). For instance, Santonja et al., (2018) reported an increase of collembolan abundance (Folsomia candida) from low temperature $\left(15{ }^{\circ} \mathrm{C}\right)$ to moderate temperature $\left(20^{\circ} \mathrm{C}\right)$ followed by a strong reduction at elevated temperature $\left(25^{\circ} \mathrm{C}\right)$ exceeding their thermal limit in a 4-week microcosm experiment. In addition, altered climatic conditions could modify the outcome of predator-prey interactions (Thakur, Künne, Griffin \& Eisenhauer, 2017; Santonja et al., 2018). For example, Lang, Rall, Scheu \& Brose (2014) reported in a 7-week microcosm experiment that both increasing temperature and decreasing soil moisture reduced Collembola prey biomass (Lepidocyrtus cyaneus and Isotoma viridis) due to an increased consumption rate of a predatory Acari (Hypoaspsis aculeifer). While numerous studies provided clear evidence of negative effects of drought conditions (e.g., Lindberg, Engtsson \& Persson 2002; Tsiafouli, Kallimanis, Katana, Stamou \& Sgardelis, 2005; Santonja et al., 2017) and of combined warmer and dryer conditions (Petersen, 2011; $\mathrm{Xu}$, Kuster, Günthardt-Goerg, Dobbertin \& Li, 2012) on collembolan populations during field experiments, only few studies used laboratory microcosm experiments. Moreover, these studies focused on the responses of a single or two collembolan species, which do not reflect natural communities and therefore limit extrapolation of the results from lab to field conditions. Experimentally controlled conditions mimicking, as far as possible, the natural conditions, are necessary to decipher the mechanisms responsible for such negative alterations.

Ecological traits, including functional, morphological, physiological or phenological traits, strongly determine the performance of soil organisms (Violle et al., 2007). Species that exhibit distinct functional traits could therefore differently respond to environmental factors (Makkonen, Berg, van Hal, Callaghan, Press \& Aerts, 2011; Salmon et al., 2014). Body size appears to be strongly influenced by shifts in climatic conditions (McGill, Enquist, Weiher \& Westoby, 2006). The temperature-size rule (TSR) (Atkinson, 1994) predicts that small body size is an adaptive advantage in response to warmer conditions (Reuman, Holt \& Yvon- 
Durocher, 2014; Lindo, 2015) since small body size is associated with a reduction of the metabolic costs that occur with thermal constraints. In addition, a smaller body size of a collembolan could be favoured over larger ones under dryer conditions since they could survive in sheltered microhabitats (Kalinkat et al., 2013; Aupic-Samain et al., 2019) including deeper soil layers (Ojala \& Huhta, 2001; Pflug \& Wolters, 2001). However, in a 60-day microcosm experiment, Thakur et al,, (2017) reported that the larger collembolan $F$. candida outperformed the smaller collembolan Proisotoma minuta under warmer conditions as gamasid mites $H$. aculeifer and Stratiolaelaps scimitus (formerly $H$. miles) exhibited a higher predation effect on small compared to large preys. In addition to the key role played by body size, the furca, i.e., the collembolan jumping organ, allows them to escape predators (Bauer \& Christian, 1987; Hopkin, 1997). Thus, in a predator-prey system, some Collembola could respond differently to the interactive effects of decreasing soil moisture and increasing temperature according to their different ability to escape predation due to some functional traits including both body size (Kalinkat et al., 2013; Thakur et al., 2017) and furca presence. However, no previous study attempted to evaluate the impact of both decreasing soil moisture and increasing temperature on a collembolan community and its response to predation, even though this type of experimentation could improve our mechanistic knowledge of soil microarthropod responses to the ongoing climate change.

To fill this gap, we investigated how low soil moisture $(60 \%$ vs. $30 \%$ soil water holding capacity), elevated atmospheric temperature $\left(15^{\circ} \mathrm{C} v s .25^{\circ} \mathrm{C}\right)$ and their interactions alter a collembolan community artificially constituted by four species ( $F$. candida, Protaphorura fimata, P. minuta and Mesaphorura macrochaeta) with distinct functional traits such as body size and furca size in an 8-week factorial microcosm experiment. In addition, we investigated how the presence of a predatory Acari (Stratiolaelaps scimitus) alters this collembolan community in combination with environmental pressures. Firstly, we hypothesize that decreasing soil moisture can reduce collembolan abundances as water availability is generally the most constraining environmental condition for soil organisms in temperate and Mediterranean ecosystems (Lindberg \& Bengtsson, 2005; Kardol, Reynolds, Norby \& Classen, 2011). Secondly, we hypothesize that increasing temperature will increase collembolan abundances under optimal soil moisture conditions (Santonja et al., 2018). Thirdly, we hypothesize that decreasing soil moisture can enhance the predatory control of the collembolan community since predatory Acari are less sensitive to desiccation than their collembolan prey (Kardol et al., 2011; Santonja et al., 2017). Fourthly, we hypothesize that increasing temperature will strengthen the predatory control of the collembolan community 
due to increasing activity leading to a higher encounter probability between prey and predator (Thakur et al., 2017; Santonja et al., 2018).

\section{Material and Methods}

\subsection{Litter and soil collection}

Litter and soil material used as substrate for soil microarthropods were collected at the $\mathrm{O}_{3} \mathrm{HP}$ (Oak Observatory at OHP) experimental field site located in the Luberon Natural Regional Park (4345'34.26"N, 5 17'57.84"E; 650 m a.s.l), in Provence, SE France. This site is covered by a Mediterranean oak forest dominated by the downy oak (Quercus pubescens Willd.) and Montpellier maple (Acer monspessulanum L.). Senescent leaves of $A$. monspessulanum were sampled from different trees in November 2017 during the litterfall period. These leaves were placed in litterbags (4-mm mesh size) and disposed at the soil surface for 2 months (from middle November to middle January) in order to allow microbial colonization (Swift, Heal, Anderson \& Anderson, 1979). After retrieval, the litter samples were pooled, dried at room temperature, frozen twice at $-18{ }^{\circ} \mathrm{C}$ for $48 \mathrm{~h}$ in order to remove only fauna. This method of defaunation has been previously used efficiently to remove soil fauna with a minimal effect on the microbial community (Poll et al., 2007; Thakur et al., 2017). The leaf litter characteristics of A. monspessulanum were determined according to the protocols described in Aupic-Samain et al., (2019). The leaf litter has a C: $\mathrm{N}$ ratio of $53 \pm 0.4$, a water holding capacity of $70 \%$ and a specific leaf area of $177 \mathrm{~cm}^{2} \mathrm{~g}^{-1}$.

Soil cores of $5 \mathrm{~cm}$ diameter $\times 5 \mathrm{~cm}$ depth were sampled in November 2017, sieved through a $2 \mathrm{~mm}$ mesh and frozen twice for $48 \mathrm{~h}$ to remove the remaining soil fauna, in particular immobile forms such as eggs and pupae (Poll et al., 2007; Thakur et al., 2015). Soil samples were autoclaved twice for $24 \mathrm{~h}$ between the two cycles at $1 \mathrm{~atm}$ and $121{ }^{\circ} \mathrm{C}$ in order to eliminate soil invertebrates and microorganisms (Alef \& Nannipieri, 1995; Trevors, 1996; Fernandez et al., 2013). Soil has a $\mathrm{C}: \mathrm{N}$ of $12.4 \pm 1.5$, organic matter of $19.2 \pm 0.6 \%$ and a $\mathrm{pH}$ of $7.1 \pm 0.05$. Soil and litter were stored in a dark room at ambient temperature until the start of the experiment.

\subsection{Mesofauna collection}

The experiment was conducted using two well-represented soil arthropod groups from the leaf litter of Mediterranean forests: a gamasid predator and collembolan prey (PoinsotBalaguer \& Kabakibi, 1987; Santonja et al., 2017; Thibaud, 2017). Due to i) the difficulty to 
easily distinguish several species from the same genus in the field, such as for example $F$. candida and $F$. fimetaria that coexist in natura, ii) the difficulties in maintaining laboratory cultures of collembolans collected in the field, and iii) the high number of individuals necessary to perform the experiment (i.e., 5120 Collembola and 640 Acari individuals), we decided to use 5 microarthropod species frequent in Mediterranean oak forests (4 Collembola and 1 Acari) from laboratory cultures (Santonja et al., 2017; personal observations).

The gamasid mite Stratiolaelaps scimitus (Acari: Laelapidae) was selected as representing predators. S. scimitus is an ubiquitous species (Karg, 1998) known as predator of Collembola (Koehler, 1999; Aupic-Samain et al., 2019). It was fed Folsomia candida during rearing.

Four collembolan species were selected according to two morphological traits: body size (large vs. small) and furca (presence vs. absence). Folsomia candida Willem, 1902 (Collembola: Isotomidae), and Protaphorura fimata Gisin, 1952 (Collembola: Onychiuridae) (GenBank acc. no. MN519200) were selected as large prey species with and without furca, respectively (Table S1). Proisotoma minuta Tullberg, 1871 (Collembola: Isotomidae) and Mesaphorura macrochaeta Rusek, 1976 (Collembola: Onychiuridae) (GenBank acc. no. MN525426) were chosen as small prey species with and without furca, respectively (Table S1). These hemi- and euedaphic (i.e., intermediate and deep soil-living) species are ubiquitous, known as microbi-detritivorous species and frequently used in laboratory experiment (Fountain \& Hopkin, 2005; Staaden, Milcu, Rohlfs \& Scheu, 2011; Thakur et al, 2017). Folsomia candida and S. scimitus were obtained from permanent laboratory cultures at Aix-Marseille University, Marseille, France, while M. macrochaeta, P. fimata and P. minuta were obtained from permanent laboratory cultures at Dep. of Bioscience, Aarhus University, Silkeborg, Denmark. All Collembola species were fed ad libitum with dry yeast pellets $\left(\right.$ Arkopharma $^{\circledR}$ ).

The five selected species were reared separately in plastic boxes $(5.5 \mathrm{~cm}$ diameter $\times 9$ cm height) containing a flat mixture of plaster of Paris and activated charcoal in a 9:1 ratio, permanently water saturated. Since Acari and Collembola have different generation times which also depend on the environmental conditions such as temperature and $\mathrm{pH}$ (FolkerHansen, Krogh \& Holmstrup, 1996; Fountain \& Hopkin, 2005; Park, 2007), individuals from each species with similar body size were carefully selected in order to synchronize the age of these organisms for the experiment. Prior to the start of the experiment, all individuals were starved for $48 \mathrm{~h}$.

This article is protected by copyright. All rights reserved 


\subsection{Experimental setup}

We tested the effects of two temperatures $\left(15{ }^{\circ} \mathrm{C}\right.$ or $\left.25{ }^{\circ} \mathrm{C}\right)$, two soil moisture conditions $(60 \%$ or $30 \%$ soil water holding capacity WHC) and two levels of predation pressure either presence or absence of a S. scimitus on the population performance of the four Collembola species and the predator. Each combination was replicated eight times and then led to the construction of 64 microcosms, i.e., 2 temperatures $\times 2$ moisture conditions $\times 2$ predator pressures $\times 8$ replicates. Ten $g$ of autoclaved soil (equivalent dry mass) were placed into the plastic cylinder experimental units $(5.5 \mathrm{~cm}$ diameter $\times 9 \mathrm{~cm}$ height $)$, i.e., microcosms, and $1 \mathrm{~g}$ of $A$. monspessulanum litter cut into small pieces $1.5 \mathrm{~cm}$ length $\times 0.5 \mathrm{~cm}$ width (equivalent dry mass) was evenly distributed on top of the soil surface. At the start of experiment, $1.7 \mathrm{ml}$ of deionized water containing a mixture of yeast and distilled water (10 $\mathrm{mg}$ of yeast in $1 \mathrm{ml}$ of deionized water) was added on top of the litter to stimulate microbial growth (Thakur et al., 2017).

Twenty individuals of each collembolan species were added to all microcosm experimental units 7 days after start of the experiment. In order to allow prey acclimation to the leaf litter and soil habitat, 20 individuals of S. scimitus were added 14 days after the start of the experiment. Every two days, the position of all microcosms were randomly rearranged and aerated by opening microcosm lid for $1 \mathrm{~min}$.

The experiment was performed during 8 weeks in climate-controlled rooms (Panasonic ${ }^{\circledR}$ MLR-352H-PE) with a 16 h: 8 h light: dark photoperiod, a constant temperature and a constant $80 \%$ air humidity. The two soil moisture levels were established by adding deionized water on soil at the start of experiment and controlled for the duration of the experiment. The control treatment corresponded to $60 \%$ of soil WHC (i.e., natural soil WHC) and the drought treatment by reducing to $50 \%$ the natural WHC of the soil (i.e., $30 \%$ of soil WHC) likely close to the worst regional climate models for the Mediterranean Basin predicting a decrease of annual precipitations (from 30 to $45 \%$ ) for the end of the $21^{\text {st }}$ century (Giorgi \& Lionello, 2008; IPCC, 2014; Polade, Pierce, Cayan, Gershunov, \& Dettinger, 2014; Tuel \& Eltahir, 2020). This corresponds to $6.0 \mathrm{ml}$ and $3.0 \mathrm{ml}$ of deionized water in $10 \mathrm{~g}$ of soil for control and drought treatments, respectively. The two temperature treatments corresponded to a low $\left(15{ }^{\circ} \mathrm{C}\right.$ day $-12{ }^{\circ} \mathrm{C}$ night $)$ and a high $\left(25{ }^{\circ} \mathrm{C}\right.$ day $-22{ }^{\circ} \mathrm{C}$ night $)$ temperature regime. The lowest temperature treatment was based on the temperature at which the four Collembola species were thermally acclimated (i.e., $15{ }^{\circ} \mathrm{C}$ ) while the highest temperature treatment was established in order to represent a high $\left(+10{ }^{\circ} \mathrm{C}\right)$ warming 
scenario based on regional climatic models (Giorgi \& Lionello, 2008; IPCC, 2014; Buckley \& Huey, 2016).

At the end of the experiment, fresh litter and soil from the 64 microcosms were separated and were transferred to Berlese-Tullgren funnels (Berlese, 1905). The litter samples were extracted for $1 \mathrm{~h}$ and the soil samples were extracted for 7 days. To collect and count remaining individuals, litter was inspected under a stereomicroscope and extracted individuals were stored in $70 \%$ ethanol before counting and identification under a binocular microscope.

\subsection{Statistical analysis}

Statistical analyses were performed using a combination of univariate techniques with R software (version 3.5.1). Significance was evaluated in all cases at $P<0.05$.

A generalized linear model (GLZ) with $\mathrm{glm}$ function and MASS R package (Ripley et al., 2013), followed by post-hoc multiple comparisons (Tukey contrasts) with the glht function and the multcomp $\mathrm{R}$ package (Hothorn et al., 2014), were used to test i) for the effects of soil moisture, temperature, predation and their interactions on the abundances of the entire Collembola population and on the 4 Collembola species separately, and ii) for the effects of soil moisture, temperature and their interactions on the predator abundance. Since response variables were count data per microcosm, we performed GLZ models with negative binomial (log link function) error distribution due to overdispersion.

\section{Results}

\subsection{Overall Collembola community response}

We collected a total of 55,095 collembolan individuals from all the microcosms with an average of 889 individuals per microcosm after 2 months (Table S2). Total collembolan abundance was $79 \%$ lower with the low compared to the high soil moisture condition (Table 1) and $48 \%$ lower in presence of the predator (Table 1 and Figure 1a). The impact of predation on total collembolan abundance was also dependent on soil moisture and temperature conditions (significant soil moisture $\times$ temperature $\times$ predation interaction, Table 1), since the abundance reduction due to predation was amplified under low compared to high soil moisture condition (Figure 1a), and especially in combination with a high temperature ($90 \%$ ). The effect of temperature treatment on total collembolan abundance was dependent on both soil moisture and predation conditions (Table 1), since total collembolan abundance was 
$49 \%$ higher at $25{ }^{\circ} \mathrm{C}$ compared to $15^{\circ} \mathrm{C}$ only under high soil moisture condition in presence or absence of a predator, but $37 \%$ lower under low moisture condition in predator presence (Figure 1a).

\subsection{Species-specific Collembola response}

Relative proportions of $F$. candida, P. fimata, P. minuta and M. macrochaeta were respectively $77 \%, 4 \%, 18 \%$ and $0.4 \%$ across all treatments. The abundances of only two Collembola species were negatively affected by the decrease of soil moisture (F. candida and P. minuta), while all species abundances were differently affected by increasing temperature (except M. macrochaeta) and reduced by predator presence (Table 1). However, several interactions between the three treatments were observed (Table 1).

The abundance of $F$. candida was reduced by $89 \%$ under low compared to high soil moisture condition (Table 1 and Figure 1b), while the abundance of $P$. minuta was reduced at low soil moisture condition except at $25{ }^{\circ} \mathrm{C}$ in predator absence (significant soil moisture $\times$ temperature $\times$ predation interaction, Table 1 and Figure 1c).

The temperature effect on $F$. candida abundance was dependent on both soil moisture and predation conditions (significant soil moisture $\times$ temperature $\times$ predation interaction, Table 1) since $F$. candida abundance was higher at $25{ }^{\circ} \mathrm{C}$ compared to $15{ }^{\circ} \mathrm{C}$ expect at low moisture condition in predator presence (Figure 1b). The abundance of $P$. minuta was $81 \%$ lower at $25{ }^{\circ} \mathrm{C}$ compared to $15{ }^{\circ} \mathrm{C}$ only at high soil moisture condition in predator absence (significant soil moisture $\times$ temperature $\times$ predation interaction, Table 1 and Figure 1c). In absence of predator, increasing temperature positively affected the abundance of $M$. macrochaeta $(+51 \%)$ (significant predation $\times$ temperature interaction, Table 1; Figure 2a) and inversely reduced by $63 \%$ P. fimata abundance (Figure $2 b$ ).

The impact of predation on $F$. candida and P. minuta depended on both soil moisture and temperature conditions (significant soil moisture $\times$ temperature $\times$ predation interaction, Table 1), since we reported no predation impact on $F$. candida abundance at low soil moisture combined to low temperature and, in the opposite, no predation impact on P. minuta abundance at high soil moisture combined to high temperature conditions. However, when significant, the predation impact on both $F$. candida and $P$. minuta abundances was higher under low compared to high soil moisture conditions (Figure $1 \mathrm{~b}$ and c). Furthermore, the significant interaction between temperature and predation treatments on $P$. fimata and $M$. macrochaeta indicated that the negative effect of predation was amplified by increasing temperature (Table 1; Figure 2a and b). 


\subsection{Predator response}

The abundance of S. scimitus was $22 \%$ lower at $25{ }^{\circ} \mathrm{C}$ compared to $15{ }^{\circ} \mathrm{C}$ (Chisquared $=10.4, P<0.001$; Table S2) but was not affected by the soil moisture treatment $($ Chi-squared $=1.0, P>0.05 ;$ Table $\mathrm{S} 2)$.

\section{Discussion}

The present experiment focused on the interactive effects of climate change (increasing air temperature and decreasing soil moisture) and predatory control on the abundance of four co-existing Collembola species. We evidenced that altered climatic conditions modify the collembolan community composition with species-specific responses. In addition, our findings highlight that soil moisture is a major driver of the collembolan community by suppressing the positive effect of increasing temperature and strengthened the predatory control of collembolan abundance.

\subsection{Climatic change alters Collembola community}

Despite a strong research interest in predicting the effects of climate change on Collembola (e.g., Thakur \& Eisenhauer, 2015; Santonja et al., 2018; Aupic-Samain et al, 2019), only few studies have focused on communities including more than one or two Collembola species especially due to the difficulties in maintaining permanent laboratory cultures of field collected collembolans. In order to reflect the complexity of natural communities, we used 4 distinct Collembola species often used in microcosm studies (e.g., Cortet, Joffre, Elmholt, \& Krogh, 2003; Cole, Staddon, Sleep, \& Bardgett, 2004; Fountain \& Hopkin, 2005; Park, 2007; Thakur et al., 2017), which responded differently to dryer and warmer conditions in the present study.

According to our first hypothesis, decreasing soil moisture strongly reduced total collembolan abundances. This finding is in agreement with previous field studies reporting a decrease in abundances with decreasing soil moisture for Collembola (Tsiafouli et al., 2005; Lindo, Whiteley, \& Gonzalez, 2012; Santonja et al., 2017). It is well known that drought may impact Collembola negatively by altering their behaviour (Verhoef \& van Selm, 1983; Hågvar, 1983) and physiological processes (Hågvar, 1983; Poinsot-Balaguer \& Barra, 1991; Holmstrup, Sjursen, Ravn \& Bayley 2001; Gundersen, Leinaas \& Thaulow, 2014) leading to higher mortality and/or lower fecundity rates. In addition, we confirmed our second hypothesis of a positive effect of increasing temperature on a collembolan community. 
However, this positive effect depended on soil moisture conditions since the abundance increased with increasing temperature only at the highest soil moisture condition, consistent with our second hypothesis. As ectothermic organisms, Collembola (Gillooly et al, 2001; Rall, Vucic- Pestic, Ehnes, Emmerson, \& Brose, 2010) can increase their activities (e.g., feeding, reproduction and growth rates) with increasing temperature but only, as we have demonstrated, when soil moisture conditions are not limiting, leading to increased total collembolan abundance. This finding confirms results from previous field experiments that reported an increase in collembolan abundance with increasing temperature only under wet soil conditions (Pflug \& Wolters, 2001; Xu et al., 2012). However, we acknowledge that twothirds of the total Collembola abundance response to climatic parameters was mainly driven by $F$. candida, which is often a dominant species under laboratory conditions, suggesting caution to an extrapolation at field community level and necessitating additional experimentations to comfort our findings.

Interestingly, we provided clear evidence of species-specific responses to both decreasing soil moisture and increasing air temperature within the collembolan community. For instance, decreasing soil moisture reduced the abundances of $F$. candida and $P$. minuta (only at low temperature), suggesting a greater drought vulnerability of Isotomidae species compared to Tulbergiidae species. Some collembolans, as reported for the Protaphorura genus, could benefit of processes allowing to prevent water loss in soil (Holmstrup \& Bayley, 2013; Holmstrup \& Slotsbo, 2018) which could explain that P. fimata was not affected by decreasing soil moisture. Also, P. fimata and M. macrochaeta are eu-edaphic species which may avoid drought period better than hemi-edaphic species by living in deeper and more moist soil layers (Hågvar, 1983). Moreover, M. macrochaeta is known to be a tolerant species to unstable environmental by shifting in reproductive strategies (e.g., sexual and parthenogenesis reproduction under stress and unstressed environmental conditions, respectively; Niklasson, Petersen, \& Parker, 2000), which could likely mitigate negative effect of decreasing moisture. An additional explanation lies in the fact that M. macrochaeta is usually recognized as an early colonizer species (Dunger, Schulz, Zimdars, \& Hohberg, 2004) and, with small body size associated with a better dispersal ability, could likely migrate to sheltered microsites against desiccating conditions. Consistent with previous field experiments, increasing temperature led to a shift in community composition (e.g., Pflug \& Wolters, 2002; Lindberg, 2003; Jucevica \& Melecis, 2005; Petersen, 2011; Daghighi, Koehler, Kesel, \& Filser, 2017) highlighting a Collembola sensitivity to warmer conditions with species-specific responses: two species were favored (F. candida and M. macrochaeta) 
and, oppositely, the two other species were disfavoured ( $P$. fimata and $P$. minuta only under optimal soil moisture conditions). These findings could be in line with some previous studies that reported a better hatching success for $F$. candida at $24{ }^{\circ} \mathrm{C}(89 \%)$ compared to $16{ }^{\circ} \mathrm{C}$ (52\%) (Marshall \& Kevan, 1962), a decline of a P. minuta population when the temperature exceeded $20{ }^{\circ} \mathrm{C}$ (Thakur et al., 2017) and an increase of M. macrochaeta abundance according to a temperature gradient from $10{ }^{\circ} \mathrm{C}$ to $23{ }^{\circ} \mathrm{C}$ (Menezes-Oliveira, ScottFordsmand, Soares \& Amorim, 2014).

\subsection{Climatic change alters predatory control of the collembolan community}

Predator-prey interactions are a key structuring force in population dynamics (Thakur et al., 2017; Laws, 2017) and understanding the effects of climate change on these interactions is of primary importance to predict field soil ecosystem responses. As expected, total collembolan abundance was halved with the presence of a gamasid predator. However, shifts in climatic parameters modified the intensity of predation impact on the collembolans and the presence of the predator also altered the response of the collembolan community to changes in climatic parameters. The predation impact on the collembolan community was strengthened with decreasing soil moisture. Indeed, the reduction of total Collembola, $F$. candida and P. minuta abundances due to predation was amplified under $30 \%$ soil WHC compared to $60 \%$ soil WHC condition, and especially in combination with the highest temperature. Moreover, the abundance of the predator was not affected by decreasing soil moisture in our experiment, which shows that gamasid predators are less vulnerable to desiccation than their collembolan prey. Thus, our laboratory results provide support to some previous field studies that reported an increase in predation pressure with decreasing precipitation in semiarid grassland (Lindberg et al., 2002; Kardol et al, 2011) and in Mediterranean forest (Santonja et al., 2017).

The positive effect of increasing temperature on $M$. macrochaeta abundance was suppressed when introducing a predator into the community. Moreover, we observed an increase of predation impact on the abundances of the three other collembolan species with increasing temperature, that was amplified in combination with decreasing soil moisture for F. candida and P. minuta. In line with these findings, Thakur et al., (2017) reported higher predation effects of the two gamasid predators, $H$. miles (S. scimitus) and $H$. aculeifer, on $F$. candida and $P$. minuta at intermediate $\left(17-20{ }^{\circ} \mathrm{C}\right)$ and high $\left(22-25{ }^{\circ} \mathrm{C}\right)$ temperatures compared to a low temperature treatment $\left(12-15{ }^{\circ} \mathrm{C}\right)$ in a 60 -day microcosm experiment. 
Santonja et al., (2018) observed also a stronger top-down control by a predatory centipede on F. candida at $20{ }^{\circ} \mathrm{C}$ and $25{ }^{\circ} \mathrm{C}$ compared to $15{ }^{\circ} \mathrm{C}$. Combining these results suggests increased feeding activity of predatory Acari due to a higher feeding requirement with increasing temperature, but also a higher mobility and thus higher encounter probability between predators and preys leading to reduced prey abundance (Vucic-Pestic et al., 2010).

\section{Conclusion}

In the present study, we provided evidence, for the first time, that climate changesimulated and predatory control effects on a complex soil arthropod community constructed by four co-existing Collembola species and a predatory Acari. We highlighted that soil moisture is a major driver of Collembola community structure. Decreasing soil moisture i) reduced total Collembola abundance, ii) suppressed the positive effect of increasing temperature and iii) strengthened the predatory control of the Collembola community especially in combination with a high temperature. The implications of our findings could be important in a climate change context as reduced soil moisture should decrease Collembola abundance and diversity involving a reduced microbial community control (e.g., grazing, dissemination) as well as a reduced prey availability for predators. Consequently, these shifts in Collembola community might have substantial consequences on the whole soil food web and on key ecosystem processes they drive (e.g., litter decomposition and nutrient cycling), especially in Mediterranean ecosystems where biological processes are already strongly limited by water availability (Le Houérou, 2006). Finally, our results are highly important since they promote the need to studying more complex systems considering distinct soildwelling species, their functional traits and their trophic interactions to better predict the ecosystem responses to the ongoing climate change.

\section{References}

Aupic-Samain, Adriane., Baldy, V., Delcourt, N., Krogh, P. H., Gauquelin, T., Fernandez, C., \& Santonja, M. (2020). Data from water availability rather than temperature control soil fauna community structure and prey-predator interactions, Dryad Digital Repository. https://doi.org/10.5061/dryad.brv15dv7

Alef, K., \& Nannipieri, P. (1995). Methods in applied soil microbiology and biochemistry. Academic Press.

Atkinson, D. (1994). Temperature and organism size-a biological law for ectotherms? Adv. 
Ecol. Res., 25, 1-54.

Aupic-Samain, A., Baldy, V., Lecareux, C., Fernandez, C., \& Santonja, M. (2019). Tree litter identity and predator density control prey and predator demographic parameters in a Mediterranean litter-based multi-trophic system. Pedobiologia, 73, 1-9. doi: 10.1016/j.pedobi.2019.01.003

Bardgett, R. (2005). The biology of soil: a community and ecosystem approach. OUP Oxford.

Bauer, T., \& Christian, E. (1987). Habitat dependent differences in the flight behaviour of Collembola. Pedobiologia. Retrieved from http//agris.fao.org/agrissearch/search.do?recordID=US201302027798

Berg, B., \& Laskowski, R. (2005). Decomposers: soil microorganisms and animals. In Litter Decomposition: A Guide to Carbon and Nutrient Turnover: Vol. 38. Advances in Ecological Research (pp. 73-100). doi: 10.1016/S0065-2504(05)38003-2

Berlese, A. (1905). Apparecchio per raccogliere presto ed in gran numero piccoli arthropodi.

Blankinship, J. C., Niklaus, P. A., \& Hungate, B. A. (2011). A meta-analysis of responses of soil biota to global change. Oecologia, 165(3), 553-565. doi: 10.1007/s00442-0111909-0

Buckley, L. B., \& Huey, R. B. (2016). Temperature extremes: geographic patterns, recent changes, and implications for organismal vulnerabilities. Global Change Biology, 22(12), 3829-3842. doi: 10.1111/gcb.13313

Chahartaghi, M., Langel, R., Scheu, S., \& Ruess, L. (2005). Feeding guilds in Collembola based on nitrogen stable isotope ratios. Soil Biology and Biochemistry, 37(9), 17181725. doi: 10.1016/j.soilbio.2005.02.006

Cole, L., Staddon, P. L., Sleep, D., \& Bardgett, R. D. (2004). Soil animals influence microbial abundance, but not plant-microbial competition for soil organic nitrogen. Functional Ecology, 18(5), 631-640. doi: 10.1111/j.0269-8463.2004.00894.x

Cortet, J., Joffre, R., Elmholt, S., \& Krogh, P. H. (2003). Increasing species and trophic diversity of mesofauna affects fungal biomass, mesofauna community structure and organic matter decomposition processes. Biology and Fertility of Soils, 37(5), 302312. doi: 10.1007/s00374-003-0597-2

Daghighi, E., Koehler, H., Kesel, R., \& Filser, J. (2017). Long-term succession of Collembola communities in relation to climate change and vegetation. Pedobiologia, 64, 25-38. doi: 10.1016/j.pedobi.2017.06.001

Dubrovský, M., Hayes, M., Duce, P., Trnka, M., Svoboda, M., \& Zara, P. (2014). Multi- 
GCM projections of future drought and climate variability indicators for the Mediterranean region. Regional Environmental Change, 14(5), 1907-1919. doi: 10.1007/s10113-013-0562-z

Dunger, W., Schulz, H.-J., Zimdars, B., \& Hohberg, K. (2004). Changes in collembolan species composition in Eastern German mine sites over fifty years of primary succession. Pedobiologia, 48(5), 503-517. doi: 10.1016/j.pedobi.2004.07.005

Fernandez, C., Santonja, M., Gros, R., Monnier, Y., Chomel, M., Baldy, V., \& BousquetMélou, A. (2013). Allelochemicals of Pinus halepensis as drivers of biodiversity in Mediterranean open mosaic habitats during the colonization stage of secondary succession. Journal of Chemical Ecology, 39(2), 298-311. doi: 10.1007/s10886-013-0239-6

Folker-Hansen, P., Krogh, P. H., \& Holmstrup, M. (1996). Effect of dimethoate on body growth of representatives of the soil living mesofauna. Ecotoxicology and Environmental Safety, 33(3), 207-216. doi: 10.1006/eesa.1996.0027

Fountain, M. T., \& Hopkin, S. P. (2005). Folsomia candida (Collembola): a "standard" soil arthropod. Annual Review of Entomology, 50(1), 201-222. doi: 10.1146/annurev.ento.50.071803.130331

Gillooly, J. F., Brown, J. H., West, G. B., Savage, V. M., \& Charnov, E. L. (2001). Effects of size and temperature on metabolic rate. Science, 293(5538), 2248-2251. doi: 10.1126/science. 1061967

Giorgi, F., \& Lionello, P. (2008). Climate change projections for the Mediterranean region. Global and Planetary Change, 63(2), 90-104. doi: 10.1016/j.gloplacha.2007.09.005

Gobat, J.-M., Aragno, M., \& Matthey, W. (2013). Le sol vivant: bases de pédologie, biologie des sols. PPUR Presses polytechniques.

Gundersen, H., Leinaas, H. P., \& Thaulow, C. (2014). Surface structure and wetting characteristics of Collembola cuticles. PLOS ONE, 9(2), e86783. doi: 10.1371/journal.pone.0086783

Günther, B., Rall, B. C., Ferlian, O., Scheu, S., \& Eitzinger, B. (2014). Variations in prey consumption of centipede predators in forest soils as indicated by molecular gut content analysis. Oikos, 123(10), 1192-1198. doi: 10.1111/j.1600-0706.2013.00868.x

Hågvar, S. (1983). Collembola in Norwegian coniferous forest soils. II. Vertical distribution. Pedobiologia.

Harte, J., Rawa, A., \& Price, V. (1996). Effects of manipulated soil microclimate on mesofaunal biomass and diversity. Soil Biology and Biochemistry, 28(3), 313-322.

Hättenschwiler, S., Tiunov, A. V., \& Scheu, S. (2005). Biodiversity and litter decomposition 
in terrestrial ecosystems. Annual Review of Ecology, Evolution, and Systematics, 36(1), 191-218. doi: 10.1146/annurev.ecolsys.36.112904.151932

Holmstrup, M, \& Bayley, M. (2013). Protaphorura tricampata, a euedaphic and highly permeable springtail that can sustain activity by osmoregulation during extreme drought. Journal of Insect Physiology, 59(11), 1104-1110. doi: 10.1016/j.jinsphys.2013.08.015

Holmstrup, M., Ehlers, B. K., Slotsbo, S., Ilieva- Makulec, K., Sigurdsson, B. D., Leblans, N. I. W., ... Berg, M. P. (2018). Functional diversity of Collembola is reduced in soils subjected to short-term, but not long-term, geothermal warming. Functional Ecology, 32(5), 1304-1316. doi: 10.1111/1365-2435.13058

Holmstrup, M., Sjursen, H., Ravn, H., \& Bayley, M. (2001). Dehydration tolerance and water vapour absorption in two species of soil-dwelling Collembola by accumulation of sugars and polyols. Functional Ecology, 15(5), 647-653. doi: 10.1046/j.02698463.2001.00565.x

Holmstrup, M, \& Slotsbo, S. (2018). Combined effects of drought and cold acclimation on phospholipid fatty acid composition and cold-shock tolerance in the springtail Protaphorura fimata. Journal of Comparative Physiology B, 188(2), 225-236. doi: 10.1007/s00360-017-1127-0

Hopkin, S. P. (1997). Biology of the Springtails: (Insecta: Collembola). OUP Oxford.

Hothorn, T., Bretz, F., Westfall, P., Heiberger, R. M., Schuetzenmeister, A., \& Scheibe, S. (2014). multcomp: Simultaneous inference in general parametric models. $R$ Package Version, 1-3.

IPCC. (2014). Climate change 2013: The physical science basis: working group I contribution to the fifth assessment report of the intergovernmental panel on climate change. Cambridge University Press.

Jucevica, E., \& Melecis, V. (2005). Long-Term Effects of Climate Warming on Forest Soil Collembola. Acta Zoologica Lituanica, 15(2), 124-126. doi: $10.1080 / 13921657.2005 .10512387$

Kalinkat, G., Brose, U., \& Rall, B. C. (2013). Habitat structure alters top-down control in litter communities. Oecologia, 172(3), 877-887. doi: 10.1007/s00442-012-2530-6

Kardol, P., Reynolds, W. N., Norby, R. J., \& Classen, A. T. (2011). Climate change effects on soil microarthropod abundance and community structure. Applied Soil Ecology, 47(1), 37-44. doi: 10.1016/j.apsoil.2010.11.001

Karg, W. (1998). Räuberisch lebende milben als teil des antiphytopathogenen potentials im 
boden. Archives of Phytopathology and Plant Protection, 31(4), 341-347. doi: $10.1080 / 03235409809383244$

Koehler, H. H. (1999). Predatory mites (Gamasina, Mesostigmata). In M. G. Paoletti (Ed.), Invertebrate Biodiversity as Bioindicators of Sustainable Landscapes (pp. 395-410). doi: 10.1016/B978-0-444-50019-9.50022-4

Lang, B., Rall, B. C., Scheu, S., \& Brose, U. (2014). Effects of environmental warming and drought on size- structured soil food webs. Oikos, 123(10), 1224-1233. doi: 10.1111/j.1600-0706.2013.00894.x

Lawrence, K. L., \& Wise, D. H. (2000). Spider predation on forest-floor Collembola and evidence for indirect effects on decomposition. Pedobiologia, 44(1), 33-39. doi: 10.1078/S0031-4056(04)70026-8

Laws, A. N. (2017). Climate change effects on predator-prey interactions. Current Opinion in Insect Science, 23, 28-34. doi: 10.1016/j.cois.2017.06.010

Lindberg, N. (2003). Soil fauna and global change-responses to experimental drought, irrigation, fertilisation and soil warming (Doctoral dissertation). Swedish University of Agricultural Sciences, Uppsala.

Lindberg, N., \& Bengtsson, J. (2005). Population responses of oribatid mites and collembolans after drought. Applied Soil Ecology, 28(2), 163-174. doi: 10.1016/j.apsoil.2004.07.003

Lindberg, N, Engtsson, J. B., \& Persson, T. (2002). Effects of experimental irrigation and drought on the composition and diversity of soil fauna in a coniferous stand. Journal of Applied Ecology, 39(6), 924-936. doi: 10.1046/j.1365-2664.2002.00769.x

Lindo, Z. (2015). Warming favours small-bodied organisms through enhanced reproduction and compositional shifts in belowground systems. Soil Biology and Biochemistry, 91, 271-278. doi: 10.1016/j.soilbio.2015.09.003

Lindo, Z., Whiteley, J., \& Gonzalez, A. (2012). Traits explain community disassembly and trophic contraction following experimental environmental change. Global Change Biology, 18(8), 2448-2457. doi: 10.1111/j.1365-2486.2012.02725.x

Le Houérou, H. N. (2006). The isoclimatic mediterranean biomes: bioclimatology, diversity and phytogeography (Doctoral dissertation). Ecologia mediterranea, 108

Makkonen, M., Berg, M. P., van Hal, J. R., Callaghan, T. V., Press, M. C., \& Aerts, R. (2011). Traits explain the responses of a sub-arctic Collembola community to climate manipulation. Soil Biology and Biochemistry, 43(2), 377-384. doi: 10.1016/j.soilbio.2010.11.004

This article is protected by copyright. All rights reserved 
Marshall, V. G., \& Kevan, D. K. M. (1962). Preliminary observations on the biology of Folsomia candida Willem, 1902 (Collembola: Isotomidae). The Canadian Entomologist, 94(6), 575-586. doi: 10.4039/Ent94575-6

McGill, B. J., Enquist, B. J., Weiher, E., \& Westoby, M. (2006). Rebuilding community ecology from functional traits. Trends in Ecology \& Evolution, 21(4), 178-185. doi: 10.1016/j.tree.2006.02.002

Menezes-Oliveira, V. B., Scott-Fordsmand, J. J., Soares, A. M. V. M., \& Amorim, M. J. B. (2014). Development of ecosystems to climate change and the interaction with pollution-Unpredictable changes in community structures. Applied Soil Ecology, 75, 24-32. doi: 10.1016/j.apsoil.2013.10.004

Niklasson, M., Petersen, H., \& Parker, E. D. (2000). Environmental stress and reproductive mode in Mesaphorura macrochaeta (Tullbergïnae, Collembola). Pedobiologia, 44(3), 476-488. doi: 10.1078/S0031-4056(04)70065-7

Ojala, R., \& Huhta, V. (2001). Dispersal of microarthropods in forest soil. Pedobiologia, 45(5), 443-450. doi: 10.1078/0031-4056-00098

Park, E. K. (2007). Effect of laboratory culture conditions on population growth of Proisotoma minuta (Tullberg) (Collembola: Isotomidae). Entomological Science, 10(2), 135-140. doi: 10.1111/j.1479-8298.2007.00207.x

Petersen, H. (2011). Collembolan communities in shrublands along climatic gradients in Europe and the effect of experimental warming and drought on population density, biomass and diversity. Soil Organisms, 83(3), 463-488.

Pflug, A., \& Wolters, V. (2002). Collembola communities along a European transect. European Journal of Soil Biology, 38(3), 301-304. doi: 10.1016/S11645563(02)01163-9

Pflug, A., \& Wolters, V. (2001). Influence of drought and litter age on Collembola communities. European Journal of Soil Biology, 37(4), 305-308. doi: 10.1016/S11645563(01)01101-3

Poinsot-Balaguer, N., \& Barra, J. A. (1991). L'anhydrobiose: un problème biologique nouveau chez les Collemboles (Insecta). Revue d'écologie et de Biologie Du Sol, 28(2), $197-205$.

Poinsot-Balaguer, N., \& Kabakibi, M. (1987). Contribution à l'étude des Collemboles des Maures (Var-France). Ecologia Mediterranea, 13(3), 115-120.

Polade, S. D., Pierce, D. W., Cayan, D. R., Gershunov, A., \& Dettinger, M. D. (2014). The key role of dry days in changing regional climate and precipitation regimes. Scientific 
Reports, 4, 4364. doi: 10.1038/srep04364

Poll, J., Marhan, S., Haase, S., Hallmann, J., Kandeler, E., \& Ruess, L. (2007). Low amounts of herbivory by root-knot nematodes affect microbial community dynamics and carbon allocation in the rhizosphere. FEMS Microbiology Ecology, 62(3), 268-279. doi: 10.1111/j.1574-6941.2007.00383.x

Rall, B. C., Vucic-Pestic, O., Ehnes, R. B., Emmerson, M., \& Brose, U. (2010). Temperature, predator-prey interaction strength and population stability. Global Change Biology, 16(8), 2145-2157. doi: 10.1111/j.1365-2486.2009.02124.x

Reuman, D. C., Holt, R. D., \& Yvon- Durocher, G. (2014). A metabolic perspective on competition and body size reductions with warming. Journal of Animal Ecology, 83(1), 59-69. doi: 10.1111/1365-2656.12064

Ripley, B., Venables, B., Bates, D. M., Hornik, K., Gebhardt, A., Firth, D., \& Ripley, M. B. (2013). Package 'mass.' Cran R.

Salmon, S., Ponge, J. F., Gachet, S., Deharveng, L., Lefebvre, N., \& Delabrosse, F. (2014). Linking species, traits and habitat characteristics of Collembola at European scale. Soil Biology and Biochemistry, 75, 73-85. doi: 10.1016/j.soilbio.2014.04.002

Santonja, M., Aupic-Samain, A., Forey, E., \& Chauvat, M. (2018). Increasing temperature and decreasing specific leaf area amplify centipede predation impact on Collembola. European Journal of Soil Biology, 89, 9-13. doi: 10.1016/j.ejsobi.2018.08.002

Santonja, M., Fernandez, C., Proffit, M., Gers, C., Gauquelin, T., Reiter, I. M., ... Baldy, V. (2017). Plant litter mixture partly mitigates the negative effects of extended drought on soil biota and litter decomposition in a Mediterranean oak forest. Journal of Ecology, 105(3), 801-815. doi: 10.1111/1365-2745.12711

Scheu, S., Ruess, L., \& Bonkowski, M. (2005). Interactions between microorganisms and soil micro- and mesofauna. In Soil Biology. Microorganisms in soils: roles in genesis and functions (pp. 253-275). doi: 10.1007/3-540-26609-7_12

Schneider, K., \& Maraun, M. (2009). Top-down control of soil microarthropods - Evidence from a laboratory experiment. Soil Biology and Biochemistry, 41(1), 170-175. doi: 10.1016/j.soilbio.2008.10.013

Staaden, S., Milcu, A., Rohlfs, M., \& Scheu, S. (2011). Olfactory cues associated with fungal grazing intensity and secondary metabolite pathway modulate Collembola foraging behaviour. Soil Biology and Biochemistry, 43(7), 1411-1416. doi: 10.1016/j.soilbio.2010.10.002

Swift, M. J., Heal, O. W., Anderson, J. M., \& Anderson, J. M. (1979). Decomposition in 
terrestrial ecosystems. University of California Press.

Thakur, M. P., \& Eisenhauer, N. (2015). Plant community composition determines the strength of top-down control in a soil food web motif. Scientific Reports, 5, 9134. doi: 10.1038/srep09134

Thakur, M. P, Herrmann, M., Steinauer, K., Rennoch, S., Cesarz, S., \& Eisenhauer, N. (2015). Cascading effects of belowground predators on plant communities are densitydependent. Ecology and Evolution, 5(19), 4300-4314. doi: 10.1002/ece3.1597

Thakur, M. P., Künne, T., Griffin, J. N., \& Eisenhauer, N. (2017). Warming magnifies predation and reduces prey coexistence in a model litter arthropod system. Proceedings of the Royal Society B: Biological Sciences. Retrieved from https://royalsocietypublishing.org/doi/abs/10.1098/rspb.2016.2570

Thibaud, J. M. (2017). Catalogue des collemboles de France. Zoosystema, 39(3), 297-437. doi: 10.5252/z2017n3a1

Trevors, J. T. (1996). Sterilization and inhibition of microbial activity in soil. Journal of Microbiological Methods, 26(1), 53-59. doi: 10.1016/0167-7012(96)00843-3

Tsiafouli, M. A., Kallimanis, A. S., Katana, E., Stamou, G. P., \& Sgardelis, S. P. (2005). Responses of soil microarthropods to experimental short-term manipulations of soil moisture. Applied Soil Ecology, 29(1), 17-26. doi: 10.1016/j.apsoil.2004.10.002

Tuel, A., \& Eltahir, E. A. B. (2020). Why is the Mediterranean a climate change hot spot? Journal of Climate, 33(14), 5829-5843. doi: 10.1175/JCLI-D-19-0910.1

Tylianakis, J. M., Didham, R. K., Bascompte, J., \& Wardle, D. A. (2008). Global change and species interactions in terrestrial ecosystems. Ecology Letters, 11(12), 1351-1363. doi: 10.1111/j.1461-0248.2008.01250.x

Van der Putten, W. H., Macel, M., \& Visser, M. E. (2010). Predicting species distribution and abundance responses to climate change: why it is essential to include biotic interactions across trophic levels. Philosophical Transactions of the Royal Society B: Biological Sciences, 365(1549), 2025-2034.

Van der Putten, W. H., Vet, L. E. M., Harvey, J. A., \& Wäckers, F. L. (2001). Linking aboveand belowground multitrophic interactions of plants, herbivores, pathogens, and their antagonists. Trends in Ecology \& Evolution, 16(10), 547-554. doi: 10.1016/S01695347(01)02265-0

Verhoef, H. A., \& van Selm, A. J. (1983). Distribution and population dynamics of Collembola in relation to soil moisture. Ecography, 6(4), 387-388. doi: 10.1111/j.16000587.1983.tb01234.x

This article is protected by copyright. All rights reserved 
Violle, C., Navas, M.-L., Vile, D., Kazakou, E., Fortunel, C., Hummel, I., \& Garnier, E. (2007). Let the concept of trait be functional! Oikos, 116(5), 882-892. doi: 10.1111/j.0030-1299.2007.15559.x

Vucic-Pestic, O., Birkhofer, K., Rall, B. C., Scheu, S., \& Brose, U. (2010). Habitat structure and prey aggregation determine the functional response in a soil predator-prey interaction. Pedobiologia, 53(5), 307-312. doi: 10.1016/j.pedobi.2010.02.003

Wardle, D. A., Bonner, K. I., \& Barker, G. M. (2002). Linkages between plant litter decomposition, litter quality, and vegetation responses to herbivores. Functional Ecology, 16(5), 585-595. doi: 10.1046/j.1365-2435.2002.00659.x

Xu, G.-L., Kuster, T. M., Günthardt-Goerg, M. S., Dobbertin, M., \& Li, M.-H. (2012). Seasonal exposure to drought and air warming affects soil Collembola and mites. PLOS ONE, 7(8), e43102. doi: 10.1371/journal.pone.0043102 


\section{Tables}

Table 1. Chi-square significance of the experimental factors and their interaction produced by the generalized linear model. The factors are soil moisture (60\% WHC and 30\% WHC), temperature $\left(15{ }^{\circ} \mathrm{C}\right.$ and $\left.25{ }^{\circ} \mathrm{C}\right)$, predation (no predator and predator presence) and their effects on collembolan abundances (total Collembola, F. candida, P. fimata, P. minuta and M. macrochaeta). Chi-square $\left(\chi^{2}\right)$ and associated $P$-values (with the respective symbols $*$ for $P<0.05, * *$ for $P<0.01$, and $* * *$ for $P<0.001)$ are indicated.

\begin{tabular}{lccccc}
\hline & Total & Folsomia & Protaphorura & Proisotoma & Mesaphorura \\
& Collembola & candida & fimata & minuta & macrochaeta \\
\hline Moisture (M) & $148.8^{* * *}$ & $180.0^{* * *}$ & 0.4 & $9.7^{* *}$ & 2.6 \\
Temperature (T) & 0.0 & $4.3^{*}$ & $118.3^{* * *}$ & $12.0^{* * *}$ & 0.2 \\
Predation (P) & $48.4^{* *}$ & $19.8^{* * *}$ & $81.7^{* * *}$ & $24.9^{* * *}$ & $65.2^{* * *}$ \\
$\mathrm{M} \times \mathrm{T}$ & $10.5^{* *}$ & $6.5^{*}$ & 0.2 & 1.4 & 0.6 \\
$\mathrm{M} \times \mathrm{P}$ & $14.7^{* *}$ & $4.2^{*}$ & 1.7 & $15.7^{* * *}$ & 0.5 \\
$\mathrm{~T} \times \mathrm{P}$ & $6.6^{* * *}$ & $13.3^{* * *}$ & $60.1^{* * *}$ & 0.7 & $5.2^{*}$ \\
$\mathrm{M} \times \mathrm{T} \times \mathrm{P}$ & $10.2^{* *}$ & $13.8^{* * *}$ & 0.2 & $9.5^{* *}$ & 2.4 \\
\hline
\end{tabular}

This article is protected by copyright. All rights reserved 


\section{Figure legends}

Figure 1. Effects of soil moisture $\times$ temperature $\times$ predation interaction on (a) total Collembola and (b) F. candida and (c) P. minuta abundances. Values are means \pm SE; $\mathrm{n}=8$. Different letters denote significant differences between treatments with $a<b<c<d<e<f$.

Figure 2. Effects of temperature $\times$ predation interaction on (a) M. macrochaeta and (b) $P$. fimata abundances. Values are means $\pm \mathrm{SE} ; \mathrm{n}=16$. Different letters denote significant differences between treatments with a $<\mathrm{b}<\mathrm{c}$. 
Figure 1.
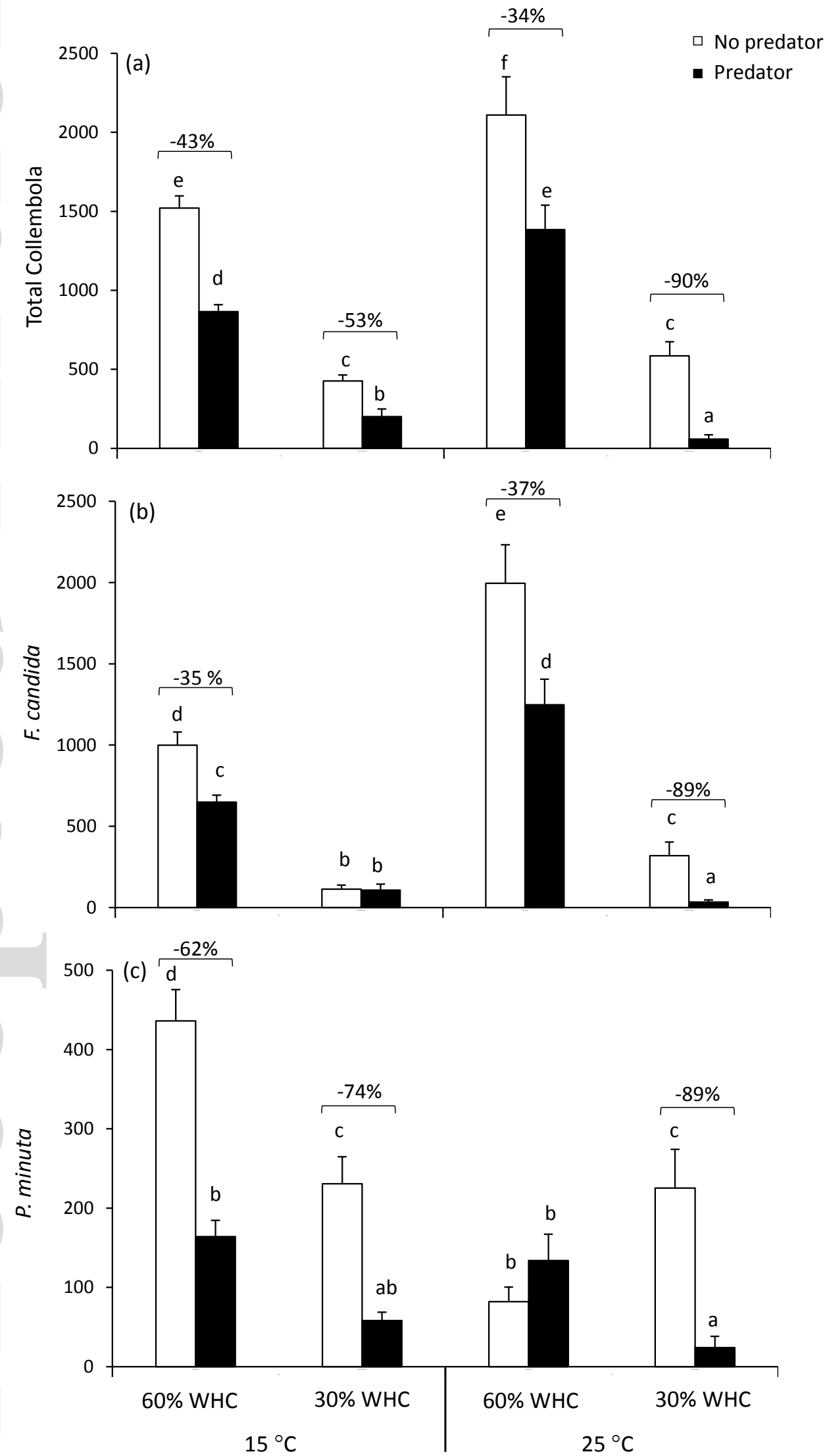

This article is protected by copyright. All rights reserved 
Figure 2.

\section{$\square$ No predator \\ - Predator}
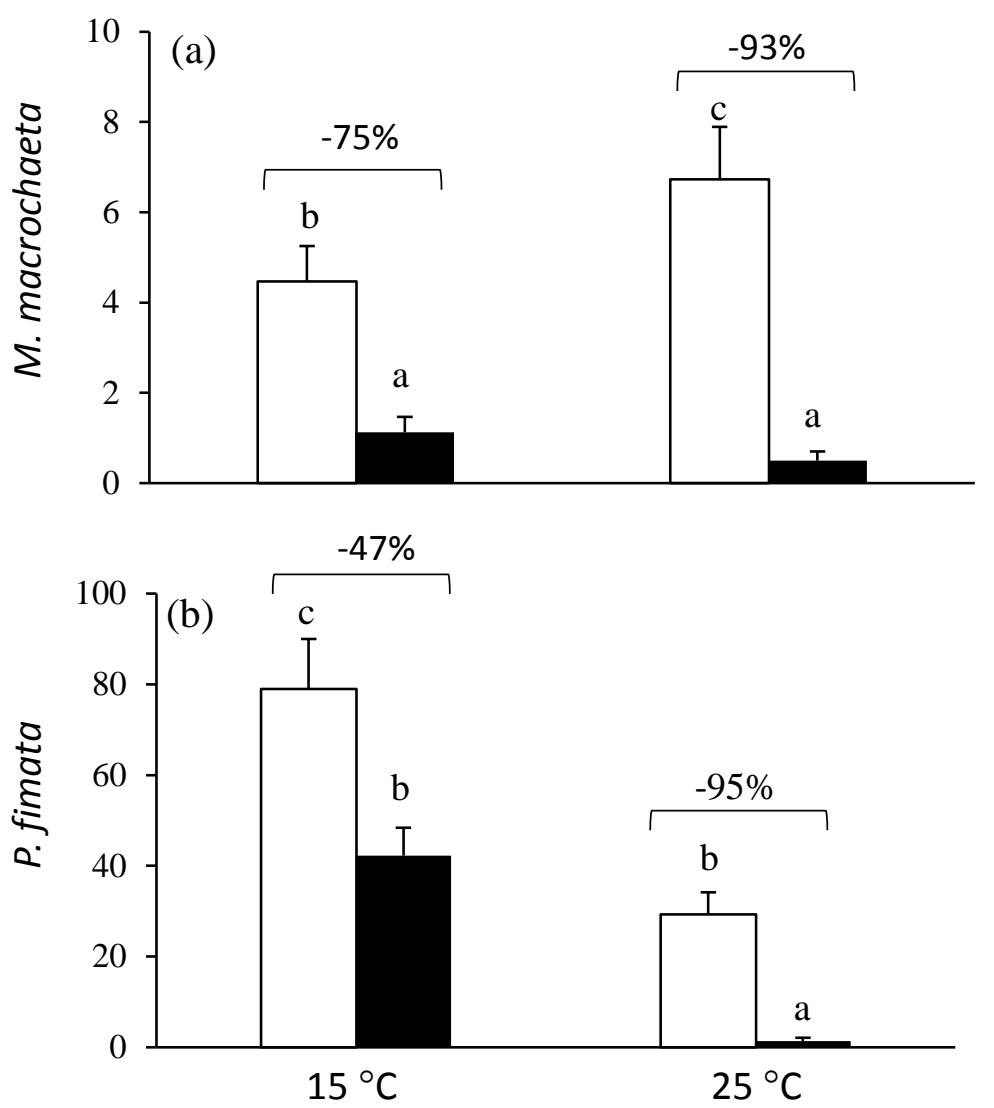

This article is protected by copyright. All rights reserved 